\title{
TRANSESTERIFICATION OF FISH OIL AND PERFORMANCE STUDY ON 4-STROKE CI ENGINE WITH BLENDS OF FISH BIODIESEL
}

\author{
Shivkumar Sirurmath ${ }^{1}$, Vikram ${ }^{2}$, Pavan $\mathbf{M}^{3}$, Govind Das ${ }^{4}$ \\ ${ }^{1}$ Professor Dept of Mechanical Engineering, SLNCE Raichur, Karnataka, India \\ ${ }^{2}$ Department of Mechanical Engineering, SLNCE Raichur, Karnataka, India
}

\begin{abstract}
The methyl esters of vegetable oils, known as biodiesel are becoming increasingly popular because of their low environmental impact and potential as a green alternative and eco-friendly fuel for diesel engine and they would not require significant modification of existing engine hardware. Fish Oil Methyl Ester or Fish Oil biodiesel is extracted from crude fish oil by the process called as "Transesterification". Experiment has been carried out to study various properties of FOME, such as Calorific value, Specific gravity, Flash point, Fire point, Viscosity etc.. for different blends of FOME (ie. B0, B20, B40, B60, B80, B100) and further this experiment includes the study of performance of 4-stroke diesel engine for various parameters such as Brake Power (BP), Brake Specific Fuel Consumption (BSFC), Brake Specific Energy Consumption (BSEC), Brake Thermal Efficiency (BTE) and Exhaust Gas Temperature (EGT).
\end{abstract}

Keywords: Fish Oil, Performance, Transesterification Process, Brake Power

$* * *$

\section{INTRODUCTION}

The world is facing an extreme dearth of non-renewable energy resources termed as "Peak Oil", while energy demands are increasing. India, like any other developing country, relies on energy for sustained growth \& development and consequently depends on crude petroleum imported from other countries to cater to the large demands of fuel in the automobile, industrial and agricultural sectors. India produced 34.11 million tonnes of crude oil in 2007-08 and imported 121.67 million tonnes of crude oil worth Rs 2726.99 billion. Our utmost dependence on petroleum fuels has resulted in soaring the Carbon dioxide $\left(\mathrm{CO}_{2}\right)$ content high in the atmosphere reaching deadly 450ppm contributes to pollution significantly. These engines are used in heavy transporting vehicles civil transporting buses and many other locomotives. In various sectors like industries, agricultural and electrical power generation. Diesel engine is a most popular prime mover for surface transportation, agricultural machineries and the industries more than 6.5million diesel engines being used in Indian agricultural sectors for various activities. Import of petroleum products is major drain our foreign exchange source and growing demand in future likely to even worst and in other point of view petroleum diesel fossil fuel and its resources are decreasing duly. Biodiesel stands as a unique substitute for conventional energy and has become the cynosure for its eco-friendly advantages. There are many attempts have been made by many researchers to explore renewable fuels (liquids \& gaseous) throughout the world. Many developed countries have tried straight vegetable oils, Micro-emulsified, thermally cracked and esterifies with or without petro-diesel blending on Freedman.B.Pryde et al [1] Pyrolysis and emulsification among these transesterification is the key and foremost important step to produce the cleaner and environmentally safe fuel from vegetable oils. Ramdas AS [2] reported that transesterification of vegetable oil to methyl ester reduces its molecular weight, viscosity and increases the cetane number.

\section{MATERIALS}

Crude marine fish oil was procured from Blue line foods India Pvt. Ltd which was extracted from the discarded parts of marine fish like viscera, fins, eyes and tails etc.. known as soap stock. The chemicals: Methanol, Orthophosphoric acid (99.8\%), Sulphuric acid (99.8\%) of Sri Ganesh Fine Chemicals and $\mathrm{KOH}(89 \%)$ of Karnataka Fine Chemicals Ltd. are used.

\section{TRANSESTERIFICATION OF FISH OIL}

The term transesterification is used as synonymous for alcoholises of carboxylic esters, in agreement with most publications in this field. The transesterification is an equilibrium reaction and the transformation occurs essentially by mixing the reactants. However, the presence of a catalyst (typically a strong acid or base) accelerates considerably the adjustment of the equilibrium. In order to achieve a high yield of the ester, the alcohol has to be used in excess [4].

\subsection{Mild Acid Catalyzed Transesterification}

The first stage removes organic matter and other impurities present in the oil in the presence of orthophosphoric acid, used as a reagent. Fish oil extracted from the MARINE FISH consist of the impurities of high quality, which were causing the 
transesterification difficulty. Hence, this necessitated the use of first stage. This is a type of reaction that takes place in the presence of methanol (30\%) and orthophosphoric acid (0.6\%) at $60^{\circ} \mathrm{c}$ with constant stirring, helps in the separation of impurities which were dissolved in the methanol as an upper layer and oil in the lower layer. The oil is separated and taken for 2nd stage.

\subsection{Strong Acid Catalyzed Transesterification}

Anhydrous sulphuric acid used as a catalyst in this stage which helps in reducing FFA content in the oil obtained from the first stage. The first stage product is reacted with the sulphuric acid $(0.6 \%)$ and methanol $(20 \%)$ for 2 hours at $60^{\circ} \mathrm{c}$ with constant stirring. The reaction product is allowed to settle. The FFA and the other impurities were removed in this stage as an upper layer and oil in the lower layer. Oil is separated and taken for 3rd stage.

\subsection{Base Catalyzed Transesterification}

The settled lower layer of the earlier stages having low FFA is used as a raw material for this stage. The product of earlier stages ie pure triglycerides is made to react with methanol (30\%), catalyst and $\mathrm{KOH}(3 \mathrm{gms})$ for 2 hours at $60^{\circ} \mathrm{C}$ with constant stirring rate. The reacted product of this third stage is made to settle down under gravity. The lower contains which contain glycerol and other impurities are removed and further excess of alcohol and other impurities present are removed by water wash process after the $\mathrm{pH}$ neutralization. The water wash product then heated above $100^{\circ} \mathrm{C}$ in order to remove the moisture content present in the FOME.

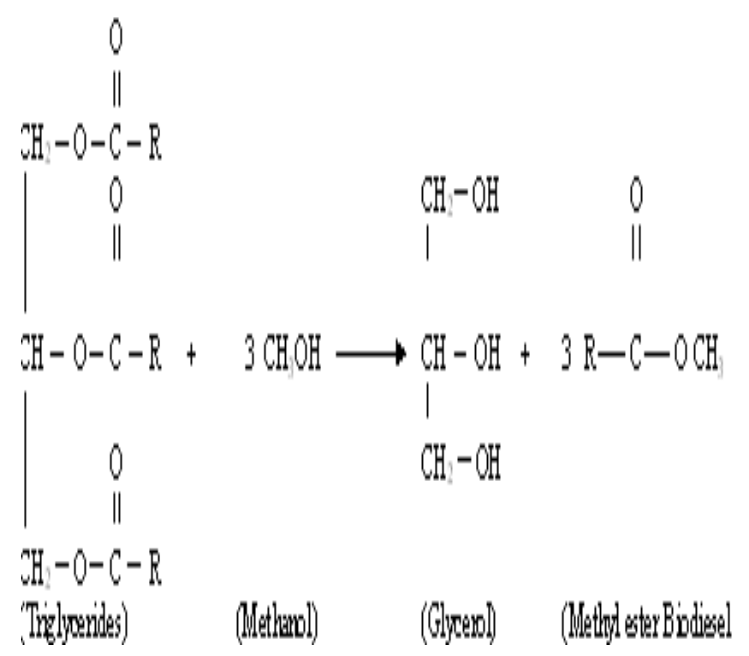

Fig-1: Equation for Transesterification Process
Table-1: Properties of fish oil biodiesel

\begin{tabular}{|l|l|l|}
\hline Sl.no & Parameters & Specifications \\
\hline 1 & Engine & $\begin{array}{l}\text { 4-stroke single cylinder } \\
\text { water cooled diesel } \\
\text { engine }\end{array}$ \\
\hline 2 & Make & Kirloskar \\
\hline 3 & Rated Power & \\
\hline 4 & Rated Speed & $1500 \mathrm{rpm}$ \\
\hline 5 & Bore X Stroke & $80 \mathrm{X} \mathrm{110}$ \\
\hline 6 & Compression Ratio & $16.5: 1$ \\
\hline 7 & Injection pressure & 200 bar \\
\hline
\end{tabular}

\subsection{Engine Setup}

The performance test has been conducted on 4-stroke direct CI engine using diesel and blends of biodiesel to study the parameters such as BP, BTE, BSFC, BSEC and EGT and compared with standard values. The layout of experimental test rig and its instrumentation is shown in Fig2.

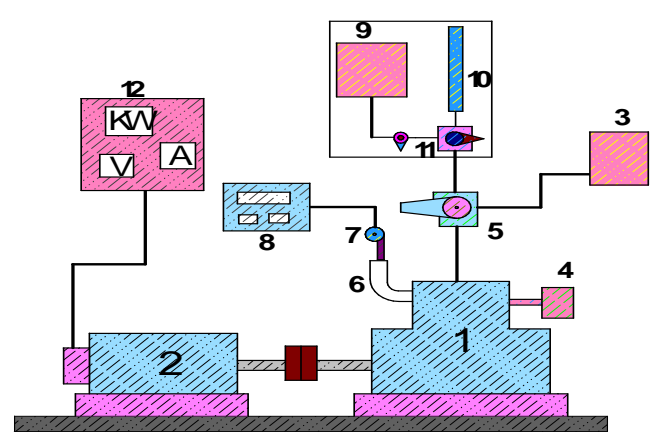

Fig-2: Experimental set up

1. Engine 2. Alternator 3. Diesel tank 4. Air filter 5. Three way valve 6. Exhaust pipe 7. Probe 8. Exhaust gas Analyzer 9. Biodiesel tank 10. Burette 11. Three way valve 12. Control panel

Table-2: Engine Specifications

\begin{tabular}{|l|l|l|}
\hline Properties & Diesel & FOME \\
\hline Specific gravity & 0.85 & 0.88 \\
\hline Kinematic viscosity at $40^{\circ} \mathrm{C}(\mathrm{cst})$ & 3.07 & 4.97 \\
\hline Flash point $\left({ }^{\circ} \mathrm{C}\right)$ & 56 & 152 \\
\hline Fire point $\left({ }^{\circ} \mathrm{C}\right)$ & 63 & 180 \\
\hline Calorific value $(\mathrm{KJ} / \mathrm{kg})$ & 42800 & 40839 \\
\hline Density $(\mathrm{kg} / \mathrm{m} 3)$ & 850 & 880 \\
\hline
\end{tabular}




\subsection{Experimental Procedure}

The biodiesel extracted from the transesterification process is used to prepare various blends by varying the concentration from zero (pure diesel) to $100 \%$ (pure biodiesel). The blends are prepared by volumetric addition of fuels. These blends are used for testing the parameters like BP, BTE (\%), BSFC, BSEC and EGT. The BSFC is not a very reliable parameter to compare two fuels as calorific values and densities of the blends shows the slight different trends. Hence we prefer BSEC as a reliable parameter for comparison to obtain optimum blend out of B0, B20, B40, B60, B80 and B100 with the help of various plots.

\section{RESULTS AND DISCUSSION}

The performance test was conducted using diesel and fish oil biodiesel (B0, B20, B40, B60, B80 and B100). The parameters such as load, torque, BSFC, fuel flow rate, BSEC, EGT, BTE observed and the results were compared.

\subsection{Brake Specific Fuel Consumption}

The BSFC of an engine for different blends of FOME is shown in fig 3. Generally it is found that with the increase in the concentration of B100 BSFC value increases and sharply decreases with the increase in the loads for all the blends. The main reasons for this could be that the percentage increase in the fuel required to operate the engine is less than the percentage increase in the brake power due to relatively less portion of heat losses at higher loads. BSFC was calculated on weight basis. Thus higher density resulted in higher value of BSFC. As density of biodiesel was higher than that diesel which means the same fuel consumption on volume basis resulted in higher BSFC in case of $100 \%$ biodiesel. The higher mass injection will occur for same volume at same injection pressure due to higher density of biodiesel or blends of FOME.

\subsection{Brake Specific Energy Consumption}

The BSEC is an ideal variable because it is independent of the fuel. Hence it is easy to compare energy consumption rather than fuel consumption. The variation in BSEC with load for all fuels is presented in fig4. In all cases, it decreased sharply with increase in percentage of load for all fuels. The main reason for this could be that percentage increase in fuel required to operate the engine is less than the percentage increase in brake power due to relatively less portion of the heat losses at higher loads. Brake specific energy consumption (BSEC) is an ideal variable because it is independent of the fuel. Hence, it is easy to compare energy consumption rather than fuel consumption.

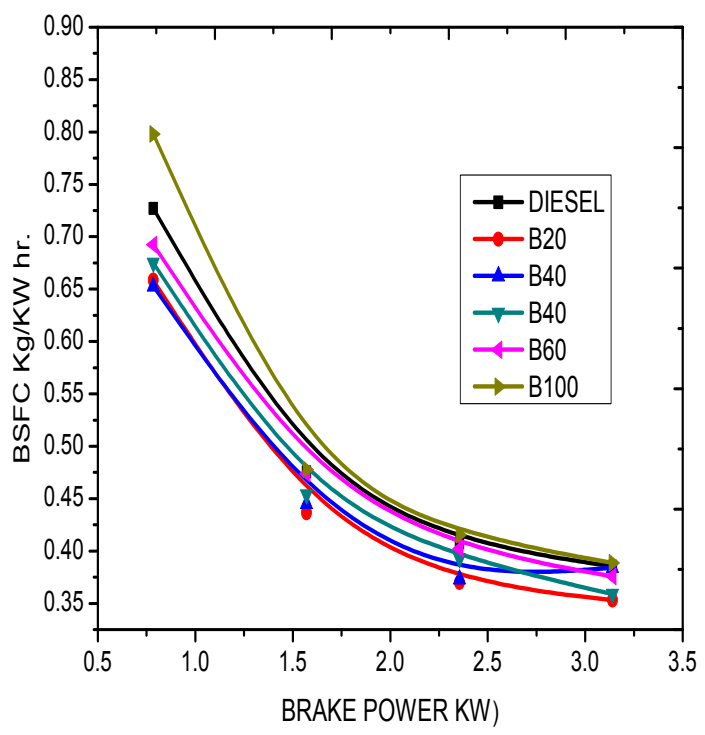

Fig-3: Comparison of BSFC with BP for diesel, FOME and its blends.

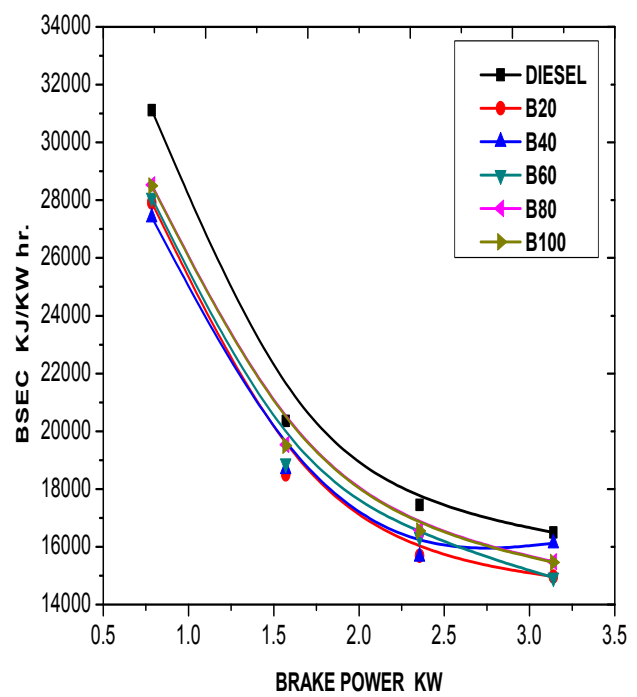

Fig-4: Comparison of BSEC with BP for diesel, FOME and its blends

The variation in BSEC with load for all fuels is presented in fig4. In all cases, it decreased sharply with increase in percentage of load for all fuels. The main reason for this could be that percent increase in fuel required to operate the engine is less than the percent increase in brake power due to relatively less portion of the heat losses at higher loads. 


\subsection{Brake Thermal Efficiency}

The graph shows that BTE increases with the increase in the load however for blends B40, B60, B80, B100 is observed that BTE is less than diesel this is due to lower calorific value of blends. However B20 has got higher value of BTE than that of diesel. Hence it is an optimum blend.

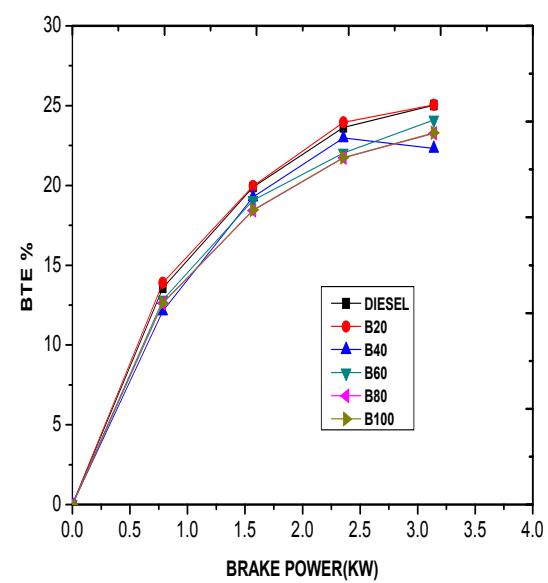

Fig-5: Comparison of TE with BP for diesel, FOME and its blends.

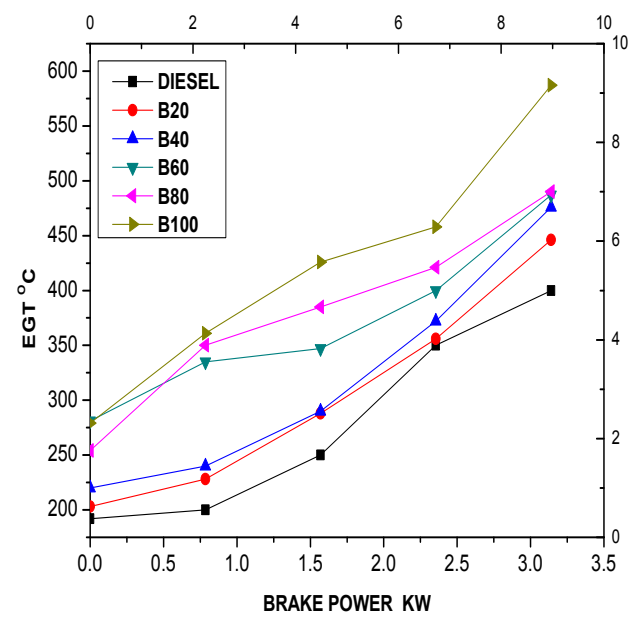

Fig-6: Comparison of EGT with BP for diesel, FOME and its blends

\subsection{Exhaust Gas Temperature}

The variations of EGT with respect to engine loading are represented in fig6. In general, the EGT increases with increase in engine loading for all the fuel tested. The mean temperature increased linearly from $1440 \mathrm{C}$ at no load to $1870 \mathrm{C}$ at full load condition. This increase in EGT with load is obvious from the simple fact that more amount of fuel was required to the engine to generate that extra power needed to take up the additional loading. The exhaust gas temperature was found to increase with the increasing concentration of biodiesel in the blends.

\section{CONCLUSIONS}

Based on the results of this study, the following specific conclusions were draw:

1. Brake specific fuel consumption for B20 is lower than the diesel fuel and it is increased as blend ratio increase.

2 The maximum thermal efficiency for B20 (31.38\%) was higher than that of diesel. The brake thermal efficiency obtained for B40, B60, B80 and B100 were less than that of diesel.

3 The exhaust temperature increased as a function of the concentration of biodiesel blend ie higher the percentage of FOME.

4 The fuel properties of fish oil biodiesel except calorific value, all other properties of FOME found to be higher compared to diesel.

\section{NOMENCLATURE}

\begin{tabular}{|c|c|}
\hline FOME & - fish oil methyl ester \\
\hline BP & - brake power \\
\hline BSFC & - brake specific fuel consumption \\
\hline BSEC & - brake specific energy consumptiol \\
\hline EGT & - exhaust gas temperature \\
\hline BTE & - brake thermal efficiency \\
\hline $\mathrm{CV}$ & - calorific value \\
\hline FFA & - free fatty acid \\
\hline B0 & - pure diesel \\
\hline B20 & $-20 \% \mathrm{BD}+80 \% \mathrm{D}$ \\
\hline B40 & $-40 \% \mathrm{BD}+60 \% \mathrm{D}$ \\
\hline B60 & $-60 \% \mathrm{BD}+40 \% \mathrm{D}$ \\
\hline B80 & $-80 \% \mathrm{BD}+20 \% \mathrm{D}$ \\
\hline B 100 & - pure biodiesel \\
\hline $\mathrm{BD}$ & - biodiesel \\
\hline D & - diesel \\
\hline
\end{tabular}

\section{ACKNOWLEDGEMENTS}

The authors acknowledge Reva Institute of Technology Bangalore for giving opportunity to carry out the experimental work. We would also like to acknowledge Dr. Sharanappa Godiganur H.O.D Mechanical engineering of RITM Bengaluru for his guidance. We would also like to acknowledge Prof. V.M.Ravindranath H.O.D Mechanical engineering and Prof .Shivkumar Sirurmath of SLNCE Raichur for his valuable suggestions, support and guidance. 


\section{REFERENCES}

[1] Freedman.B,Pryde EH, Mountus TL-Variables affecting the yield of fatty acid esters from vegetable oils. JAOCS 1984;61(10):1638-43

[2] Ramdas AS, Jayaraj S, Muralidharan C. Biodiesel production from high FFA Rubber seed oil. Fuel,2005;84:335-40.

[3] H. Lu, Y. Liu, and H. Zhou. Production of biodiesel from jatropha curcas L. oil. Computers and Chemical Engineering 33 (2009) pp. 1091-1096.

[4] Ramadhas AS, Muraleedharan C, Jayaraj S. Performance and emission evaluation of a diesel engine fueled with methyl esters of rubber seed oil. Renewable Energy 2005;30:1789-800.

[5] Puhan S, Vedaraman N, Ram BVB, Sankarnarayanan G, Jeychandran K. Mahua oil (Madhuca indica seed oil) methyl ester as biodiesel-preparation and emission characteristics. Biomass Bioenergy 2005;28:87-93.

[6] Biodiesel Fuel Production by Methanolysis of Fish Oil Derived from the Discarded Parts of Marine Fish. -Anil Kumar Patil*, Sharanappa Godiganur**, Rana Pratap Reddy**_"International Journal of Scientific \& Engineering Research, Volume 4, Issue 4, April-2013 1855 ISSN 2229-5518"

[7] Performance and Emission Characteristics of a Kirloskar HA394 Diesel Engine Operated on Mahua Oil Methyl Ester -Sharanappa Godiganur, Ch. Suryanarayana Murthya and Rana Prathap Reddyb-“Thammasat Int. J. Sc. Tech., Vol. 15, No. 3, July-September 20 